\title{
Importancia pronóstica del estado nutricional basal y de la respuesta inflamatoria sistémica en pacientes con cáncer de pulmón de célula no pequeña (CPCNP)
}

- Andrés Felipe Cardona, Andrea Rusi, Leonardo Rojas, Beatriz Wills, Christian Castro, Luis Gerardo García-Herreros, Carlos Vargas, Hernán Carranza, Jorge Otero, Óscar Arrieta

Clínica del Country, Fundación para la Investigación Clínica y Molecular Aplicada del Cáncer (Ficmac), Bogotá, D.C. Contacto: a_cardonaz@yahoo.com

\begin{abstract}
Introducción y objetivos. El estado nutricional y la respuesta inflamatoria afectan la evolución del CPCNP metastásico. El objetivo fue evaluar el valor pronóstico de la proteína $C$ reactiva $(P C R)$, dímero $D(D D)$, ceruloplasmina (CP) y albúmina sérica (AS).

Materiales y métodos. Se incluyeron 98 casos en los que se determinaron los niveles de PCR, DD, CP y AS antes del inicio de la primera línea y después de 3 y 6 meses de intervención. Se evaluó la relación entre el nivel basal y su variación temporal, con diversos desenlaces (TRG, SLP, SG).

Resultados. La edad media fue de 65 años $(D E \pm 11)$, el $70 \%$ fueron mujeres, el $83 \%$ tenían adenocarcinoma y el $89 \%$ tenían un IK $>70 \%$. Inicialmente el $52 \%, 43 \%, 53 \%$ y $34 \%$ tenían niveles anormales de $C P, D D, A S$ y $P C R$, respectivamente. Los pacientes con baja AS $(p=0,004)$, alto $D D(p=0,012)$ y PCR anormal $(p=0,040)$ tuvieron una TRG menor con la quimioterapia de primera línea. En el análisis bivariado, aquellos con elevación de la PCR (HR 1,67; IC95\% 1,28-2,69; $p=0,008)$ y del DD (HR 2,56, IC95\% 01,05-03,04, $p=0,006)$ tuvieron una SLP inferior; así mismo, los pacientes con PCR (HR 1,9; IC95\% 1,04-02,01; $p=0,04)$ y albúmina anormales (HR 2,9; IC95\% 2,1-4,6; $p=0,03)$ tuvieron una repercusión significativa en la SG. La AS + PCR afectaron de forma independiente la SG.
\end{abstract}

Conclusiones. La inflamación y nutrición afectan la SG en pacientes con CPCNP metastásico.

\section{Experiencia en el uso de catéteres centrales de inserción periférica en una institución de cuarto nivel en Colombia, 2011-2014}

\author{
Patricia Vélez, Sandra Liliana Millán, Juan Guillermo Restrepo, Alexandra Cossio
}

Fundación Valle del Lili, Cali (Valle del Cauca).

Contacto: pvelez@fcvl.org

Introducción y objetivos. El incremento del uso de catéteres centrales de inserción periférica (PICC, por su sigla en inglés) en adultos en el país hace necesario documentar los resultados de esta práctica. Se describe la experiencia del uso de PICC en una institución de cuarto nivel.

Materiales y métodos. Estudio descriptivo de una cohorte de 1.474 PICC en pacientes mayores de 16 años. Variables sociodemográficas, clínicas y complicaciones fueron incluidas en el análisis, se calcularon medidas de tendencia central, proporciones y tasas de complicaciones. Prueba chi cuadrado utilizada para establecer diferencias entre complicaciones y variables clínicas. La aprobación ética fue obtenida.

Resultados. Se colocaron 1.474 catéteres en cuatro años, el 50\% fueron hombres, edad Me (rango): 57 (19-88) años, hospitalizados $79 \%$ y ambulatorios $21 \%$, pacientes oncológicos $52 \%$. Las indicaciones de uso fueron quimioterapia (47\%) y TPN/medicamentos, sitio de inserción: vena basílica (56\%) y cefálica (42\%), ubicación radiológica vena cava superior (90\%), sin complicación en la inserción en el $85 \%$ y se utilizó ultrasonido en el $10 \%$. La duración del catéter Me (rango): 34 (2-351) días. El porcentaje y tasa de complicaciones globales fueron del $9 \%$ y 1,4/1.000 días catéter, las principales complicaciones fueron salida accidental, infección, trombosis: $2,6 \%, 2,1 \%$ y $1,3 \%$, respectivamente, y las tasas fueron $0,4 / 1.000$, $0,3 / 1.000,0,27 / 1.000$. Hubo diferencias significantes entre complicaciones y condición de accesos vasculares, sitio y lado de inserción, ubicación radiológica, especialidad e indicación del catéter.

Conclusiones. El uso de catéteres PICC es una alternativa para la administración de quimioterapia y medicamentos de mediana duración, tiene bajas tasas de complicaciones, las cuales podrían disminuirse con el uso de ultrasonido. 